\title{
Efectividad de los Personajes de Marca. Caso: Sector Cervecero Venezolano
}

\author{
Narváez Luengo, Fernando Carlos* \\ Loreto Ron, Juan Luis** \\ Saavedra Torres, José Luis***
}

\section{Resumen}

El presente artículo tiene como objetivo explorar la efectividad de los Personajes de Marca, a través de los componentes teóricos de la creación de marcas, el capital de marca y el comportamiento del consumidor; utilizando el sector cervecero como referencia. La investigación cualitativa aplicada, adoptó un muestreo no probabilístico por conveniencia empleando la técnica de grupos focales. Los resultados permitieron determinar el consumo y la actitud hacia el consumo de bebidas alcohólicas; así como la percepción y la actitud hacia los personajes de marca, utilizados en el sector cervecero. Los resultados obtenidos permiten concluir que en el caso del sector cervecero, los personajes de marca representan un recurso efectivo, especialmente cuando se realiza una adecuada personificación del mismo y una adecuación al entorno del segmento de referencia; ya que poseen una alta capacidad de establecer relaciones con el consumidor. Contradictoriamente, y muy a pesar de su capacidad para crear recordación de marca, no se consiguieron evidencias contundentes sobre un efecto directo de los personajes de marca sobre las ventas; lo que lleva a afirmar que, en el sector cervecero, este recurso promocional no necesariamente es determinante para incrementar las ventas de los productos.

Palabras clave: Personajes de marca, marca, comportamiento del consumidor, sector cervecero.

\section{Recibido: 16-02-04 Aceptado: 06-03-06}

* Master en Administración (IESA, 2004). Especialista de Mercadeo, Banca Empresas y Personas, Coordinación de Segmentos. Banco Mercantil.E-mail:f_narvaez73@hotmail.com

** Master en Administración (IESA, 2004). Oficina Tecno-Política de la Alcaldía de Chacao.

*** Master en Administración (IESA, 1999), Profesor Asociado-Invitado de Mercadeo, FCES-LUZ. 


\title{
Effectiveness of the Brand Spokesfigure. Case: Venezuelan Beer Sector
}

\begin{abstract}
The main objective of this article is to explore the effectiveness of the brand spokesfigure through the theoretical components of brand building, brand equity and consumer behavior, using the beer market as a reference. The applied qualitative research adopted a non-probabilistic sampling for convenience, using the technique of focus groups. The results permitted determining the consumption and attitude toward the consumption of alcoholic beverages as well as the perception and attitude toward the brand spokesfigures used in the beer sector. The results obtained led to the conclusion that in the case of the beer market, the brand spokesfigure represents an effective resource, especially when it has been personified adequately and has been adapted to the environment of the reference sector, since it possess a high capacity for establishing relations with the consumer. Contradictorily, and quite in spite of its capacity to create a brand image, no powerful evidence was found regarding a direct effect of the brand spokesfigure on sales, which leads to the affirmation that, in the beer market, this promotional resource is not necessarily a determinant for increasing product sales.
\end{abstract}

Key word: Brand spokesfigure, brand, customer behavior, beer sector .

\section{Introducción}

Desde que el primer anuncio pagado surgió en 1704 y que Volney B. Palmer estableciera la primera agencia de publicidad en Estados Unidos en 1884, hasta nuestros días, la publicidad se ha convertido en la herramienta de mercadeo más utilizada de forma global. En ese entorno surgen los Personajes de Marca, como una forma de representar las bondades de un producto o servicio a una audiencia de muy bajo nivel intelectual o incluso, analfabeta a través de recursos gráficos y humorísticos (Klein y Donaton, 2003).

El primer personaje de marca moderno fue lanzado en 1920 cuando la empresa Minessota Valley Cannign Company colocó en la etiqueta de las latas de su nueva variedad de guisantes dulces una imagen de un Gigante Verde. El impacto fue tan abrumador que treinta años des- pués nadie recordaba cual era el nombre de la compañía, mientras que si recordaban y reconocían el nombre Gigante Verde. Esto llevó a Minessota Valley Cannign Company a cambiar su nombre por Green Giant Company (Compañía Gigante Verde) (Klein y Donaton, 2003).

A partir del "Gigante Verde", los Personajes de Marca han representado el vehículo para enlazar dos realidades similares pero distantes. Por un lado, las motivaciones individuales de los consumidores para adquirir productos $\mathrm{y} / \mathrm{o}$ servicios; y por el otro, los esfuerzos comunicacionales de las compañías para transferir los posibles significados de un producto $\mathrm{y} / \mathrm{o}$ servicio de forma coherente $\mathrm{y}$ entendible (Belch y Belch, 1998). La promoción y la publicidad juegan el papel de transferir el concepto simbólico a través de la asociación del producto o servicio con la representación simbólica del mis- 
mo (Leigh y Gabel, 1992). El resultado esperado es un incremento en las ventas, motivado a la actitud favorable hacia el producto, por ello la inversión asociada a los personajes de marca alcanzó un 35\% de los 400 billones de dólares invertidos en publicidad y promoción a nivel mundial en el 2004 (Initiative Futures, 2005).

En este contexto, nace la tesis central del presente artículo que es explorar la efectividad de los Personajes de Marca en un sector específico (cervecero) que haya realizado importantes inversiones en conceptos de publicidad y promoción de marca. Para lograrlo se presentó un análisis del impacto de éstos personajes en las actitudes de un grupo de consumidores específico en cuatro aspectos: a) capacidad de los personajes de marca para establecer relaciones emocionales con el consumidor, b) personificación del icono o personaje de marca por el consumidor, c) diseño del mensaje enviado y finalmente d) el impacto en las ventas.

Para explorar estas interrogantes se realizó una investigación fundamentada en principios holográficos-cualitativos, con criterios de verdad basados en obtención de datos generados por la experiencia viva y cotidiana de cada persona desde su individualidad, por la aplicación de grupos focales y en un tratamiento racionalista de la información, a través de la triangulación, el diferencial semántico y el análisis hermenéutico.

El basamento teórico se fundamenta en la Matriz de Creación de la Marca de Tybout y Carpenter (2002), la Teoría de Capital de Marca (Aaker, 1992; Keller, 1993) y la Teoría del Comportamiento del Consumidor (Engel-Blackwell-Miniard, 1990; Sheth et al, 1999) haciendo énfasis en las actitudes del consumidor impulsadas por el uso de Personajes de Marca.

\section{Concepto de Marca}

Técnicamente, una marca es un nombre y/o señal cuya finalidad es identificar el producto de un vendedor o grupo de vendedores, para diferenciarlo de los productos rivales (Stanton, et. al 2000:264). Sin embargo este concepto, tan solo presenta la visión funcional del término. Según Gallo (2000:122) una marca es la representación de lo que el consumidor entiende por garantía de que el producto que recibe es confiable, bueno para usar y consumir. Las marcas son un elemento ubicuo de los tiempos modernos, ya que existen porque ofrecen valor a los consumidores, al asegurar un nivel de calidad, simplificar un proceso de elección y, especialmente, al constituirse en los medios para que los individuos consigan una gran cantidad de metas en su vida privada y pública, desde necesidades fisiológicas básicas, así como autorrealización personal (Aaker, 1992; KeIler, 1993; Belch y Belch, 1998; Stanton, et. al 2000; Tybout y Carpenter, 2002).

Todos los beneficios que reciben los consumidores a través de las marcas, también son una fuente de riqueza tangible para las organizaciones, ya que estas características intangibles ofrecen una plataforma para la ventaja competitiva y la obtención de ganancias futuras al proveer de menores costos de adquisición, mayores niveles de retención de clientes debido a mayores niveles de lealtad de marca; así como mayor eficiencia y efectividad en los esfuerzos de mercadeo, 
mayor disposición del consumidor a aceptar mayores precios, generando a su vez un aumento de los ingresos y utilidades; y finalmente una base sólida para extensiones de línea (Saavedra, 2004).

El valor de una marca reconocida se ha ido incrementando cada vez más, hasta superar el valor de los activos tangibles netos de una compañía (Seetharaman, et al. 2001). En el 2004, la firma consultora ha catalogado el valor de la marca Coca Cola en 67 billones de dólares, siendo este monto el $59 \%$ del valor de las acciones de la empresa en el mercado bursátil. Para empresas como Nike o Apple con valores de marca en 9 y 7 billones de dólares, éste monto significa el $77 \%$ de su capitalización en bolsa (Fernández, 2002; Brady et al. 2004).

Más allá del nombre, el logotipo y los aspectos financieros; una marca es un concepto que debe ser creado y que amerita una inversión importante de tiempo, recursos y esfuerzo. Al inicio son nombres sin ninguna importancia para el consumidor; pero con el transcurrir del tiempo, estos nombres y las marcas que simbolizan llegan a representar poderosas asociaciones en la mente de los consumidores (Tybout y Carpenter, 2002; Saavedra, 2004). Aaker (1992) define estas Asociaciones como una serie de emociones, imágenes, sonidos, entre otros; que vinculados al recuerdo de marca, ayudan a los consumidores a recuperar información archivada en su mente para tomar decisiones y le proveen una razón para adquirir el producto.

Se puede afirmar entonces que las Asociaciones creadas por el consumidor impulsadas por los esfuerzos de de mercadeo de las organizaciones son las res- ponsables que una persona se vea estimulada y motivada a adquirir el producto. De allí es que se afirma que marcas con altos niveles de asociación positiva logran incrementar significativamente sus ventas, y que es a través de las marcas (y su logo, sus íconos y/o personajes) donde las empresas mantienen un crecimiento constante o mantenido de sus ventas en el mercado (Boone y Kurtz, 2003; Grant, 2000; Stanton et al., 2000).

Podemos concluir afirmando que una marca es una asociación que realiza el consumidor, y que es creada a través de los esfuerzos de mercadeo de la empresa comercializadora del productomarca. Esto nos lleva a la pregunta ¿cómo se crean las marcas? y ¿qué papel juegan los Personajes o Iconos de Marca como vínculo entre la marca-producto y el consumidor?

\section{Matriz de Creación de la Marca (Tybout y Carpenter, 2002)}

La construcción de una marca es un proceso complejo, que esta guiada por la visión del posicionamiento deseado y que se pone en práctica por medio de todas las decisiones de mercadeo y cuya importancia varía en función del tipo de marca que cada organización desee crear. La Matriz de Creación de la Marca presenta tres tipos de marcas posibles: Marcas Funcionales, Marcas de Imagen y Marcas de Experiencia (Tybout y Carpenter, 2002:120).

\subsection{Marcas Funcionales}

Son marcas adquiridas para satisfacer necesidades funcionales: lavar la 
ropa, aliviar el dolor, entre otros. Las asociaciones que experimentan los consumidores con estas marcas están relacionadas con los rasgos físicos y las funciones básicas del producto. Estas marcas están estrechamente asociadas en la mente de los compradores con categorías de productos definidas (p. ej. Ace es un detergente) y dentro de esa categoría comparten asociaciones comunes entre varias marcas (p. ej. Ace y Ariel: jabones en polvo, productos de calidad, económicos y vienen en bolsas). (Aaker, 1992; Joachimsthaler y Aaker, 2002; Tybout y Carpenter, 2002).

Las marcas funcionales tiene sólo dos formas para diferenciarse de la competencia: ofrecer funcionamiento (desempeño) o rentabilidad (economía) superior; por lo que es necesario concentrar todos los recursos en el producto (mayor desempeño) o en el lugar y precio de los elementos de mercadeo (mayor ahorro interno). El papel de la publicidad es reforzar las conexiones entre la marca y la categoría de producto y comunicar qué es lo que hace a esa marca superior a las demás. En el caso de las marcas funcionales, la publicidad no es la base de la diferenciación (Tybout y Carpenter, 2002:123).

\subsection{Marcas de Imagen}

Este tipo de marca crea valor proyectando una imagen. A pesar que los productos que representan dichas marcas son excelentes, la categoría a la que pertenecen son relativamente indiferenciados o es difícil evaluar la calidad de forma objetiva ( $p$. ej. cerveza, consultoría) o su consumo es visible para el entorno del consumidor (p. ej. vehículos, zapatos). En estos casos, las imágenes asociadas a la marca agregan valor en términos de distinguirla de otras marcas, como símbolo de la pertenencia a grupos, estilos de vida o éxitos sociales obtenidos. Cual sea el caso, el conjunto de imágenes asociadas a la marca es lo que define su carácter único y genera señales que son altamente valoradas por los consumidores (Tybout y Carpenter, 2002).

La base de diferenciación de las marcas de imagen es la publicidad, que comúnmente crea asociaciones emocionales sin apoyarse demasiado en los rasgos de los productos ( $p$. ej. botella de Coca Cola) o los personajes o iconos usados (p. ej. hombre Marlboro). El objetivo es crear imágenes centrándose en el consumidor de la marca, ya que, en la interpretación compartida de estos usuarios de lo que representa usar la marca, radica el valor de la misma. El éxito es hacer una conexión emocional con los consumidores, para lo que se deben crear asociaciones atemporales en la mente del consumidor lo que amerita un alta inversión en tiempo y en dinero (Tybout y Carpenter, 2002).

\subsection{Marcas de Experiencia}

Las marcas de experiencia difieren de las marcas de imagen en términos de énfasis. Las marcas de experiencia se centran en como se sienten los consumidores cuando entran en interacción con la marca; con una combinación de producto, servicio y entorno para crear encuentros temporales sensoriales de marca. La experiencia es creada por la marca y el consumidor en el momento del consumo y en consecuencia es única y personal (Tybout y Carpenter, 2002:131).

Las marcas de experiencia se conectan con el deseo del consumidor, cen- 
trándose en experiencias y metas que los enriquezcan. Interactuar con la marca es un fin en si mismo y no un medio para llegar a alguna meta (p. ej. ropa marca Ferrari). Por ello, además del producto (tangible o no), los componentes de "lugar" y "gente" de entrega de servicios son particularmente importantes para crear marcas de experiencias fuertes (p. ej. Tony Romas).

El éxito de las marcas de experiencia se basa en dos aspectos. Primero, generar la capacidad organizacional de recrear la experiencia de marca, impulsando a las empresas a desarrollar competencias de reclutamiento, formación de personal, manejo de sistemas de información y procedimientos; por lo que la inversión de dinero se centra básicamente en el factor humano que rodea a la marca. El segundo aspecto de éxito es la capacidad de la marca para producir, como si fuera la primera vez, la intensidad de la satisfacción a la tercera o cuarta experiencia del cliente.

Finalmente Tybout y Carpenter (2002) exponen que una marca alcanza su valor real cuando las asociaciones que genera la marca se convierten en parte de la vida de los compradores, al residir en su mente, ya que sin ellas, la marca se convierte en un nombre sin sentido. Esto nos lleva a una pregunta ¿cómo se crean estas asociaciones en la mente del consumidor?

\section{Actitudes, Capital de Marca y Comportamiento del Consumidor}

Las Asociaciones son el tema central del estudio del Capital de Marca. De hecho, Sheth, et al. (1999:710) define al Capital de
Marca como el estudio de las asociaciones y el valor de la marca por parte del consumidor. Aaker (1992) las define como la serie de emociones, imágenes, sonidos, entre otros; vinculados al recuerdo de la marca, que ayudan a los clientes a recuperar información archivada en su mente para tomar decisiones, proveyéndoles una razón para adquirir el producto, generándoles sentimientos positivos.

El Capital de Marca, tiene cinco dimensiones: desempeño, imagen social, valor, credibilidad e identificación. En la definición de cada uno de ellos, los teóricos del capital de marca (Farquhar, 1989; Aaker, 1992; Keller, 1993; Low y Lamb Jr., 2000) han definido una relación directa entre las Asociaciones y las Actitudes del consumidor, tema éste último que ha sido estudiado a profundidad por la Teoría de del Comportamiento del Consumidor y el proceso de toma de decisiones de compra (Engel et al, 1990; Loudon y Della Bitta, 1995; Sheth et al, 1999; Ratneshwar et al, 2000; Bagozzi et al, 2002; Solomon, 2003).

El modelo "Toma de Decisiones de Compra" describe el comportamiento del consumidor como un proceso de cinco etapas: 1) Reconocimiento de la Necesidad, 2) Búsqueda de Información, 3) Evaluación de Alternativas, 4) Compras y 5) Comportamiento Post-Compra (EngelBlackwell-Miniard, 1990). Las actitudes aparecen en este modelo en la tercera etapa, cuando al obtener la información de las distintas alternativas de productos y servicios, el consumidor pasa a evaluar cada una de ellas sobre la base de sus creencias y actitudes. Este proceso genera una intención de compra para la 
marca que recibió la valoración más favorable (Engel-Blackwell-Miniard, 1990).

Las actitudes son predisposiciones aprendidas como respuesta a objetos o clases de objetos en forma consistentemente favorable o desfavorable (Sheth, et al, 1999:388). Las actitudes son un tamiz para filtrar la información que el consumidor considere de valor y poseen cuatro características: 1) Son aprendidas, por lo que la información que recibe diariamente un consumidor de sus grupos de referencia, de imágenes de marca, de líderes políticos; contribuyen a formar dicha actitud. 2) Tienen un Objeto, ya que la actitud sólo se presenta hacia algo específico y en concreto. 3) Tienen dirección e intensidad, ya que las actitudes son positivas o negativas (nunca neutrales) y tienen fuerza. 4) Tienden a ser estables y generalizables, ya que una vez formadas tienden a perdurar en el tiempo y cuanto más tiempo se mantengan, más resistentes al cambio (Aaker 1992; Sheth, et al, 1999; Ratneshwar et al, 2000; Bagozzi et al, 2002; Sheth et al, 2003; Solomon, 2003).

Sheth, et al (1999) clasifican los componentes de las actitudes en tres tipos: Sentimientos (afecto, rechazo), Pensamiento (creencias y expectativas de desempeño) y Acción (reconocimiento de las bondades del producto por uso o experiencia). Para las primeras dos clasificaciones el consumidor nunca a consumido el producto o lo ha hecho en pocas oportunidades y su actitud viene aprendida por su entorno y sus grupos de influencia (que recomiendan o aconsejan dejar usarlo). Estos tres componentes generan una jerarquía de actitudes que es usada ampliamente por los profesionales de mercadeo.

\section{Jerarquía de Actitudes}

Los componentes de las actitudes no tienen un valor o una posición de mayor importancia entre sí. Lo interesante a determinar por los profesionales de marketing es el orden de aparición de cada uno de los componentes, ya que esto permite relacionar más estrechamente la actitud con el comportamiento de compra, lo que significa pronosticar mejor futuros resultados de ventas (Sheth, et al, 1999; Schmitt, 1999; Grant, 2000).

\subsection{Jerarquía Racional: Pensar-Sentir-Actuar}

El orden de los componentes en Pensamiento primero, luego Sentimientos y finalmente, Acción; crea la Jerarquía Racional. En ésta, las expectativas y creencias acerca del producto son la primera base de análisis para la toma de decisiones (p. ej. Vehículos, computadoras, medicinas no preescritas). Una vez satisfecha la parte racional, se da paso al componente afectivo y es solo al final que el consumidor toma la decisión (acción) de compra del producto (Sheth, et al, 1999; Schmitt, 1999; Grant, 2000).

\subsection{Jerarquía Emocional: Sentir-Actuar-Pensar}

La combinación de los componentes en la Jerarquía Emocional adjudica una especial importancia al componente afectivo y emocional del consumidor, al colocar este componente de primero en el orden de comportamiento (i.e. dulces, ropa). Una vez explorado el aspecto emocional de la toma de decisión, el consumidor pasa a la Acción y tan sólo al final interviene el componente racional del pen- 
samiento (Sheth, et al, 1999; Schmitt, 1999; Grant, 2000).

La Jerarquía Emocional al igual que la Jerarquía Racional forman parte de las Jerarquías de Alta Implicación, ya que son productos que generan fuertes sentimientos de aceptación o rechazo, y/o que ameritan un análisis racional para determinar si son aceptados, ya que poseen un alto grado de vinculación para con el consumidor (Sheth, et al. 1999; Rodríguez, et al. 2000; Ratneshwar et al, 2000; Bagozzi et al, 2002; Sheth et al, 2003; Solomon, 2003).

El concepto de implicación proviene del campo de la socio-sicología y la incorporación del constructo al campo de la sicología del consumidor se produjo con los trabajos de Krugman (1965, 1966, 1966-67), quien define la implicación como el grado de importancia personal que una persona le adjudica a un objeto, producto o servicio (Sheth, et al. 1999:361) o el estado de motivación o excitación del individuo derivado de una percepción del estímulo de relevancia personal (Rodríguez, et al. 2002).

\subsection{Jerarquía de Baja Implicación: Actuar-Sentir- Pensar}

La combinación de los componentes en la Jerarquía de Baja Implicación asume que la actitud del consumidor no posee una actitud positiva o negativa de gran intensidad, por lo que las consecuencias de su consumo no son tan importantes para él (p. ej. azúcar, sal). Por ello, el orden comienza con la Acción, seguido del componente emocional para finalizar en el pensamiento.

\section{Estudio de la Efectividad de los Personajes de Marca}

Partiendo de la construcción teórica antes analizada, para la realización del estudio de la efectividad de los personajes o íconos de marca se estructuraron tres etapas en el procedimiento de investigación: 1) Selección de un tipo de producto/servicio que cumpliera las definiciones teóricas: Tipo de Marca de Imagen (Tybout y Carpenter, 2002) y Jerarquía de Alta Implicación de tipo Emocional (Sheth, et al., 1999); 2) Selección de un sector de actividad económica con características: múltiples marcas, altos niveles de recordación, altos niveles de inversión publicitaria en el tiempo, utilización de personajes o íconos de marca y universo de estudio de fácil acceso; 3) Selección del método de recolección de datos y diseño del instrumento y 4) Selección de la muestra. El orden de estas etapas fue vinculante y para pasar de una a otra era necesario haber cumplido los pasos y procedimientos de la etapa anterior.

\subsection{Selección del Producto y/o Servicio de Referencia}

Para efectos de la investigación se analizaron diferentes tipos de productos y/o servicios que cumplieran las características de Tipo de Marca de Imagen (Tybout y Carpenter, 2002) y Jerarquía de Alta Implicación de tipo Emocional (Sheth, et al., 1999). Para ello se seleccionó inicialmente los productos con Tipo de Marca de Imagen. En esta primera revisión fueron seleccionados los siguientes productos: Cigarrillos, Cervezas, Automóviles, Perfumes, Ropa Femenina, 
Refrescos, Comida Rápida y Centros Comerciales.

Posteriormente se cruzaron los productos seleccionados con la característica de Jerarquía de Alta Implicación de tipo Emocional, quedando seleccionados finalmente: Cigarrillos, Cervezas, Automóviles, Perfumes, Ropa Femenina y Refrescos.

Y por último, la revisión teórica determinó al sector Cervecero, y más concretamente a la categoría "Cerveza Tipo Pilsen" como altamente informativa pues cubría a cabalidad los requerimientos impuestos por el equipo investigador: múltiples marcas (Polar, Regional y Brahma), altos niveles de recordación ya que aparece dentro de las 5 categorías de mayor nivel de recordación, según la revista especializada Publicidad y Mercadeo (2004), altos niveles de inversión publicitaria en el tiempo (más de 500 millones de bolívares invertidos en el año 2005), utilización extensa de personajes o íconos de marca (Vicente Pedroso por Polar, la Catira por Regional y el Cangrejo Ñaña Ñaña por Brahma) y un universo de estudio de fácil acceso.

La competencia en el sector cervecero venezolano ha hecho que las compañías adopten nuevas estrategias, modernicen su comunicación y cambien aspectos básicos de su negocio. Las tres empresas participantes en el sector han utilizado Personajes o Íconos de Marca como estrategia comunicacional: 1) En el 2002, Cervecería Polar hizo un cambio de imagen, destacando el hecho que su icono de marca (el oso polar) se pusiera en pié. En el 2003, el animal cobra vida y hasta adquiere nombre: Vicente Pedroso. 2) Cervecería Regional, mantiene desde 1995 su campaña de "La Catira Regional" para apoyar el crecimiento de su cerveza Pilsen y 3) En el 2002, Brahma lanzó su campaña "Ñaña, Ñaña" donde el icono de marca utilizado para impulsar a su cerveza tipo Pilsen es un simpático cangrejo generado por computadora.

\subsection{Selección del método de recolección de datos y diseño del instrumento}

Se determinó el empleo de la técnica de la entrevista a través de métodos cualitativos directos, como lo son los grupos de enfoque, ya que se consideró que era la manera más eficiente para recopilar los datos, dada la naturaleza del estudio y el tipo de información a obtener: las percepciones, actitudes y asociaciones de los personajes e íconos de marca. (Loudon y Della Bitta, 1995; Sheth, et al. 1999; Benassini, 2001).

La guía de temas planteada para los Grupos de Enfoque contenía dos grandes aspectos a explorar entre los entrevistados: A) Consumo y Actitud hacia el consumo. En este apartado se revisaron los siguientes puntos: Actividades que realizan en el tiempo libre, lugares que frecuentan, bebidas alcohólicas preferidas, ocasión de consumo y preferencia por marcas de cerveza y volumen de consumo.

B) Percepción y Actitud hacia los personajes e íconos de marca. En este apartado se revisaron los siguientes puntos para cada uno de los tres personajes analizados (Oso Pedroso, Catira Regional y Cangrejo Ñaña, Ñaña): Recordación espontánea, asociación con el personaje, recordación del personaje, si el personaje fuera una persona ¿cómo se- 
ría?, identificación con el personaje y entre los tres personajes, ¿cual considera mejor y porque?

\subsection{Diseño de la Muestra}

Debido a la inexistencia de bases de datos o record de consumidores de cerveza de forma generalizada y constante por los expendidos de bebidas o las empresas productoras, se utilizó la técnica de muestreo no probabilístico accidental (Sabino 2000).

Las variables para definir la población objeto de estudio, especialmente, la del rango etario, fueron tomadas de la conceptualización de "Heavy-User" (clientes de alto consumo) utilizada en los planes de mercadeo del segmento de cerveza Pilsen, de las empresas Cervecería Polar y Cervecería Regional, información suministrada por Melillo (2004) vicepresidente creativo de Concept-Lowe Publicidad que lleva la cuenta publicitaria de Cerveza Polar. La población quedó definida como todas aquellas persona residentes en la ciudad de Caracas, de ambos sexos, con niveles educativos desde bachillerato hasta profesionales de tercer nivel, pertenecientes a estratos socioeconómicos $\mathrm{C}$ y $\mathrm{D}$, y con edades comprendidas entre los 20 y 35 años de edad.

Al tratarse de un estudio cualitativo, el tamaño de la muestra no es un factor determinante para la obtención de los resultados, por lo que se decidió tomar cuatro grupos de personas, dos de mujeres y dos de hombres, cada uno de clases sociales $C$ y $D$, de diez personas cada uno para un total de 40 individuos. Utilizando un muestreo no probabilístico se eligieron a criterio del equipo investigador los cuatro grupos tomando en cuenta la disponi- bilidad, hábito conocido de consumo de bebidas alcohólicas y accesibilidad a las zonas residenciales de los entrevistados, especialmente en los consumidores del estrato D. Los Grupos de Enfoque se realizaron durante el mes de Mayo del 2004.

\section{Resultados}

Los resultados fueron agrupados en dos grandes grupos, ya que cada uno explica diferentes aspectos del comportamiento del consumidor: Por un lado, se encuentran los resultados concernientes al consumo y la actitud hacia el consumo de las bebidas alcohólicas, especialmente la cerveza; y por el otro, la percepción y la actitud hacia los personajes e íconos de marca, utilizados en el sector cervecero.

En cuanto al consumo y la actitud hacia el consumo de bebidas alcohólicas, los resultados encontrados nos permiten observar que los individuos entrevistados poseen objetivos específicos a la hora de consumir cervezas, y que consideran a esta bebida como un medio para lograrlos. Este hallazgo confirma la teoría del consumidor que afirma que los productos y servicios son instrumentales por su capacidad de representar satisfactores de necesidades fisiológicas y psicológicas (Ratneshwar et al, 2000; Bagozzi et al, 2002; Sheth et al, 2003; Solomon, 2003).

Al observar la ocasión de consumo de los hombres del estrato $D$, podemos inferir que su principal motivación hacia el producto es de recompensa, ya que éstos mencionaron que toman cerveza luego de una jornada de trabajo, si les va bien en el día, o cuando gana un juego de básquet (ya que el equipo perdedor debe pagar con cerveza). Esto indica que para 
este grupo, el consumo del producto tiene una connotación más individual que grupal y puede ser clasificada como una necesidad de auto-reconocimiento. El consumo individual después de una jornada diaria o luego de ganar un partido, es visto como una recompensa personal asociado a un mecanismo de reforzamiento de la autoestima (Loudon y Della Bitta, 1995; Ratneshwar et al, 2000; Bagozzi et al, 2002; Sheth et al, 2003; Solomon, 2003).

Este objetivo instrumental de consumo, muestra un claro contraste con los individuos que representan al estrato $\mathrm{C}$, ya que estos manifestaron que su consumo de cerveza esta ligado a ocasiones sociales como ir a la playa o salir a sitios nocturnos. Aquí la ocasión de consumo es referida como una forma de compartir con amigos y compañeros. En éste caso, la motivación responde a una herramienta de filiación y pertenencia, como una forma de pertenecer a un grupo de referencia. Los hombres de estrato $\mathrm{C}$, al igual que las mujeres de ambos estratos, manifestaron frecuentar lugares públicos como las Discotecas, la playa y los centros comerciales. Pero también hicieron hincapié en frecuentar los hogares de los amigos. Sólo los hombres de estrato D, manifestaron el hecho frecuentar únicamente los lugares públicos, sin hacer ninguna mención explicita en frecuentar los hogares de amigos. Un resumen de los hallazgos más importantes se presenta en Tabla 1, que presenta los seis aspectos a considerar dentro del tema de consumo y la actitud hacia el consumo; en orden descendente partiendo de la respuesta que obtuvo la mayor frecuencia de menciones durante el grupo de enfoque.
En cuanto a los resultados obtenidos en el tema de la percepción y la actitud hacia los personajes e íconos de marca, se agrupan los resultados por personaje. Para identificar claramente las afirmaciones de los consumidores, se anexan entre paréntesis expresiones espontáneas recogidas durante el grupo de enfoque.

\subsection{Víctor Pedroso (Polar)}

Los individuos de clase D asociaron a Pedroso con un ambiente de fiesta, cerveza, el Oso y la marca Polar. A nivel de a recordación espontánea, entre los hombres hubo continuas menciones sobre las chicas que rodean al Personaje, recordando especialmente las versiones de cuñas de "La Playa y El Buceo". En este punto, puede identificarse que los individuos muestran una proyección de su "yo ideal" ya que esta condición pudiera estar asociada a un modelo o ejemplo a seguir dentro de los patrones culturales de este grupo de individuos (Solomon, 2003). Además de ello pudieron recordar versiones de comerciales de televisión, y en algunos casos fueron recordados frases y diálogos de los mismos, lo que demuestra que tanto el lenguaje como las situaciones presentadas por el Personaje, están en sintonía con el espectro cultural y las creencias de los entrevistados.

En cuanto a la descripción de la personalidad de Pedroso, los hombres de estrato $D$ mencionaron características que parecieran describir a una serie de anti-valores como: irresponsable y mujeriego (expresiones como "Es el popular de la cuadra, jugador de caballos, rumbero e irresponsable"). A pesar de ello, se le considera como popular y divertido. Las mujeres de este estrato lo describieron fí- 


\section{Tabla 1}

\section{Percepción y actitud hacia el consumo. Sector Cervecero Venezolano}

\section{Grupos de Enfoque}

\begin{tabular}{|c|c|c|c|c|}
\hline & $\begin{array}{l}\text { Hombres } \\
\text { Clase D }\end{array}$ & $\begin{array}{l}\text { Mujeres } \\
\text { Clase D }\end{array}$ & $\begin{array}{c}\text { Hombres } \\
\text { Clase C }\end{array}$ & $\begin{array}{l}\text { Mujeres } \\
\text { Clase C }\end{array}$ \\
\hline $\begin{array}{l}\text { Actividades que realizan } \\
\text { en el tiempo libre }\end{array}$ & $\begin{array}{l}\text { Deportes: bás- } \\
\text { quet béisbol } \\
\text { Tomar con } \\
\text { amigos/chi- } \\
\text { cas, Jugar ca- } \\
\text { ballos }\end{array}$ & $\begin{array}{l}\text { Bailar, } \\
\text { Ir a la playa } \\
\text { Tomar con } \\
\text { las amigas }\end{array}$ & $\begin{array}{l}\text { "salir a beber" } \\
\text { "Io que salga } \\
\text { con los panas" } \\
\text { Deportes: fút- } \\
\text { bol básquet, } \\
\text { rugby }\end{array}$ & $\begin{array}{l}\text { Ir a la playa, } \\
\text { Bailar y to- } \\
\text { mar cerveza } \\
\text { Ir a casa de } \\
\text { amigos }\end{array}$ \\
\hline Lugares que Frecuentan & $\begin{array}{l}\text { Playa. } \\
\text { Centro Comer- } \\
\text { cial, (ferias co- } \\
\text { mida y video- } \\
\text { juegos) Disco- } \\
\text { teca }\end{array}$ & $\begin{array}{l}\text { Discoteca } \\
\text { Fines de se- } \\
\text { mana con } \\
\text { amigas para } \\
\text { oír música, } \\
\text { hablar y to- } \\
\text { mar }\end{array}$ & $\begin{array}{l}\text { Casa de ami- } \\
\text { gos Lugares } \\
\text { públicos (es- } \\
\text { tacionamien- } \\
\text { to) Discoteca, } \\
\text { Cine, Casa de } \\
\text { familiares }\end{array}$ & $\begin{array}{l}\text { Playa } \\
\text { Discotecas } \\
\text { Sitios para } \\
\text { jugar dominó } \\
\text { Cine y Cen- } \\
\text { tro Comer- } \\
\text { cial }\end{array}$ \\
\hline $\begin{array}{l}\text { Bebidas alcohólicas } \\
\text { preferidas }\end{array}$ & $\begin{array}{l}\text { Anís, Vodka, } \\
\text { Cerveza, Gua- } \\
\text { rapa y el Ale- } \\
\text { xander }\end{array}$ & $\begin{array}{l}\text { Ginebra, } \\
\text { el "Alexan- } \\
\text { der", Tenta- } \\
\text { ción, Coan- } \\
\text { troe, Anís }\end{array}$ & $\begin{array}{l}\text { Cerveza, } \\
\text { Whisky, Gine- } \\
\text { bra, Guarapi- } \\
\text { ta, Anís, Caci- } \\
\text { que, Vodka }\end{array}$ & $\begin{array}{l}\text { Cerveza, } \\
\text { Ginebra, } \\
\text { Calua, } \\
\text { Brize Ice }\end{array}$ \\
\hline Ocasión de Consumo & $\begin{array}{l}\text { En la Playa, al } \\
\text { salir a bailar, } \\
\text { luego de hacer } \\
\text { deporte o de } \\
\text { un día duro de } \\
\text { trabajo }\end{array}$ & $\begin{array}{l}\text { Disfrute con } \\
\text { amistades o } \\
\text { pareja. Pla- } \\
\text { ya. }\end{array}$ & $\begin{array}{l}\text { La playa o en } \\
\text { las cercanías } \\
\text { de su lugar de } \\
\text { estudio, o en } \\
\text { sitios públicos } \\
\text { (plaza y esta- } \\
\text { cionamiento) }\end{array}$ & $\begin{array}{l}\text { Con grupo } \\
\text { de amigos } \\
\text { Discotecas } \\
\text { En casas de } \\
\text { familiares } \\
\text { sin motivo } \\
\text { claro }\end{array}$ \\
\hline $\begin{array}{l}\text { Preferencia por marcas de } \\
\text { cerveza }\end{array}$ & $\begin{array}{l}\text { Brahma Light } \\
\text { Polar Pilsen } \\
\text { Re gional Light } \\
\text { Solera }\end{array}$ & $\begin{array}{l}\text { Regional, } \\
\text { Brahma } \\
\text { Light Polar } \\
\text { Ice }\end{array}$ & $\begin{array}{l}\text { Polar Ice } \\
\text { Solera } \\
\text { Brama X } \\
\text { Polar Pilsen } \\
\text { Regional Light }\end{array}$ & $\begin{array}{l}\text { Polar Ice, } \\
\text { Regional } \\
\text { Brize Ice }\end{array}$ \\
\hline Volumen de Consumo & $\begin{array}{l}\text { Promedio: } 10 \\
\text { unidades. (bai- } \\
\text { lando } 20 \text { y ju- } \\
\text { gando o ha- } \\
\text { blando 15) }\end{array}$ & $\begin{array}{l}\text { Promedio: } \\
\text { entre } 5 \text { y } 10 \\
\text { cervezas. }\end{array}$ & $\begin{array}{l}\text { Promedio: en- } \\
\text { tre } 8 \text { y } 15 \text { cer- } \\
\text { vezas, depen- } \\
\text { de del precio }\end{array}$ & $\begin{array}{l}\text { Promedio: } \\
\text { entre } 5 \text { u } 8 \\
\text { cervezas }\end{array}$ \\
\hline
\end{tabular}

Fuente: Elaboración propia (2004). 
sicamente atractivo y como una persona extrovertida y amigable. Estos indicios pudieran estar indicando que para ese grupo, los anti-valores representan a un tipo de comportamiento socialmente aceptado por el grupo, siendo de esta forma, antagónicamente aceptado.

En cuanto a los hombres de estrato $\mathrm{C}$, las características personales de Pedroso están asociadas a un su desenvolvimiento social que implica diversión. Además de ello se le identificó con ciertos oficios y ocupaciones característicos de un estrato inferior a los del grupo. A diferencia de los del grupo de estrato $D$, los entrevistados identificaron al personaje siempre dentro de un contexto de celebración entre amigos. Los individuos del estrato $\mathrm{C}$, describieron al personaje de forma individual, otorgándoles características más específicas que lo describen como persona ("Esta buenote", "Es cuadra'o", "Un poco calvito", "De piel blanca", "Buen mozo").

Con respecto a los factores de identificación, los hombres de clase D, manifestaron que Pedroso es un compañero solo para ocasiones de diversión, pero por las características negativas mencionadas anteriormente, Pedroso no es una persona cuya amistad vale la pena cultivar ("...nooo... Pedroso, sólo para el momento, ese bicho es una rata..."). Los hombres y mujeres del estrato $C$ mencionaron que Pedroso representa la jocosidad y la viveza del venezolano ("No tiene compromisos", "No trabaja, es un flojo", "Es un Borracho de Plaza que cae bien pero no es buen ejemplo para nadie").

Hubo consenso entre todos los individuos en ubicar la edad de Pedroso entre los 30 y 35 años. Con respecto a la proce- dencia del personaje, se mencionó que éste sería oriental o caraqueño con mayor frecuencia, pero unos pocos mencionaron que Pedroso podría ser maracucho.

\subsection{La Catira (Regional)}

Con respecto a La Catira, la recordación espontánea en los hombres de estrato $D$, no estuvo relacionada a la marca ni al producto, sino a anécdotas populares con relación al personaje, que parecieran estar relacionados a las creencias y actitudes del grupo ó que pudiera funcionar como un mecanismo que trate de develar el ambiente de misterio que encierra la identidad del Personaje de marca ("No muestra la cara por que a la primera la mataron por eso, la violaron en el Ávila"). En cuanto a las mujeres, si hubo relación entre el personaje y la marca Regional. Además de ello, las mujeres pudieron recordar hasta tres de las versiones de. Como que ésta tiene un cuerpo diferente al que ellas están acostumbradas a ver, pero que es producto de continuas cirugías.

Aunque la organización selectiva del mensaje fue distinta entre hombres y mujeres de este estrato, si hubo coincidencia en cuanto a la Interpretación selectiva de los estímulos, específicamente al hecho de que La Catira no muestre su rostro, es asumido por el grupo como una señal de superioridad y prepotencia frente a los demás ("Es sifrina", "cae mal", "odiosa", "creída").

Otra coincidencia entre los géneros, fue el hecho de considerar a La Catira en un estrato socioeconómico superior, mencionando inclusive algunas características de su estilo de vida ("come muy bien", "es modelo", "va al club", "vive 
en la lagunita"). Estas asociaciones tienen un sentido negativo ya que según los participantes, La Catira trata de demostrar que es mejor que el entorno que lo rodea. Los hombres calcularon la edad de la catira entre los 25-33 años, mientras las mujeres lo hicieron entre los 22-27 años de edad.

En cuanto a los Hombres del estrato $\mathrm{C}$, las asociaciones con La Catira fueron abiertamente sexuales ("Esta buena"). Sin embargo, este estrato considera que el personaje es "arrivista" ya que ha conseguido un bienestar económico, no por sus meritos intelectuales sino por su físico. Incluso se comentó que anteriormente la catira llevaba una vida muy dura pero a través de su atractivo físico, pudo lograr tener una vida mejor. ("Tiene 30 años, Peliteñida, está casada con un hombre poderoso y antes de estar con ese hombre llevaba una vida de locura). En este punto hubo discrepancia con los individuos del segmento $D$, ya que éstos últimos piensan que La Catira pertenece, de origen, a estratos sociales superiores y no por haber experimentado movilidad social. La edad de La Catira para los individuos de $C$, fue calculada entre los 23 y 27 años. No se mencionaron tantos descriptores sociales, como los individuos de estrato $D$, pero si se mencionaron algunos oficios $u$ ocupaciones del personaje como promotora de eventos.

En todos los estratos se mencionó que La Catira es posiblemente un hombre con cuerpo de transformista, lo que nos indica que los estándares estéticos mostrados por el personaje, no están en sintonía con los del grupo entrevistado, a tal punto que la interpretación de esos estí- mulos es completamente distorsionada y negativa.

En el estrato $D$ no hubo elementos de identificación con el personaje, mientras en el estrato $C$ si hubo algunos elementos de identificación, especialmente en los hombres, que encuentran algunas similitudes en su estilo de vida con el de los entrevistados.

\subsection{El Cangrejo Ñaña, Ñaña (Brahma)}

Los hombres de estrato $D$ asociaron de forma efectiva al personaje con la marca brama y ésta a su vez con personas de un nivel socioeconómico superior al de ellos, a través de la interpretación de ciertos símbolos utilizados en las cuñas como el tipo de traje de baño y las locaciones donde se desarrollan las cuñas, como las playas de arena muy blanca y despejadas, las cuales pudieran hacer contraste con las playas abarrotadas y poco limpias que éste grupo pudieran frecuentar ("Es otro tipo de gente, se ve clarito", "Es de mas caché, se ve en la playa, los bikinis, la piscina").

Hubo consenso en que la marca Brahma es sinónimo de distinción y estatus. Por el contrario, la recordación de los individuos de clase $\mathrm{C}$, estuvo relacionada con asociaciones negativas hacia el personaje de marca, por considerar que éste ya no presenta ninguna novedad ("Fue innovador, pero ya es fastidioso").

En cuanto a sus características personales, ambos estratos coincidieron en que el cangrejo sería una persona deshonesta que siempre trata de aprovecharse de los demás, otorgándole inclusive características de una persona que esta bajo el efecto del alcohol, con un rango de edad entre 20-25 años ("Como 
cualquiera de nosotros, cuando estamos borrachos y ya no tenemos mas dinero, esperando que alguien se descuide y quitarle el trago").

Las mujeres del Estrato D, manifestaron agrado por las cuñas de Brahma, pero sin profundizar ni identificar que tipo de elementos le parecían más atractivos. Con respecto al personaje, mencionaron que les parecía muy pícaro, identificándose con ese elemento en particular, pero no se hizo menciones negativas al respecto en comparación a los hombres. Comentaron que el cangrejo de ser una persona, tendría entre 18 y 20 años.

Las mujeres del estrato $\mathrm{C}$, consideraron al cangrejo como un personaje pícaro que le gusta estar de fiesta todo el tiempo. Las asociaciones fueron generalmente positivas ("Esta emperezando a tomar", "Cree que el mundo se va a acabar y todo es rumba").

\section{Conclusiones}

Determinar el consumo y la actitud hacia el consumo de las bebidas alcohólicas; así como la percepción y la actitud hacia los personajes e íconos de marca, utilizados en el sector cervecero, permite dar respuesta al objetivo del trabajo: Explorar la efectividad de la utilización de los Personajes o Iconos de Marca. Si bien los resultados no constituyen un elemento de inferencia para la población venezolana, es interesante evaluar los hallazgos en: a) la capacidad de los personajes de marca para establecer relaciones emocionales con el consumidor, b) personificación del icono de marca con el consumidor, c) diseño del mensaje enviado y finalmente d) el impacto en las ventas.
En primer lugar, la investigación demostró que en el caso del sector cervecero, los personajes de marca representan un recurso que puede ser efectivo, ya que poseen la capacidad de transmitir los valores de marcas a través de una conexión afectiva con los consumidores, logrando de esta forma establecer una comunicación constante y mantenida con un nivel de recordación muy prolongado. Los hallazgos de recordación espontánea (sin ayuda auditiva o visual) de características específicas, de situaciones vividas en las cuñas y la capacidad de los entrevistados de construir (y completar) el entorno social y económico de los personajes; son una muestra del alto nivel de asociación que los personajes de marca han establecido con el consumidor, confirmando la Teoría de Capital de Marca (Farquhar, 1989; Aaker, 1992) y del Comportamiento de Consumidor (Bagozzi et al., 2002; Sheth et al., 2003), al asumir que este tipo de asociación contribuye a generar un mayor nivel de recordación y percepción en los consumidores.

La segunda de las consideraciones extraídas de la investigación, es la importancia de seleccionar la personificación adecuada para el personaje de marca. Si se desprende del punto anterior, que la capacidad de establecer relaciones emocionales con el consumidor es básico para la construcción de la marca, entonces resulta más efectivo atribuirle al personaje las características que representen los valores de la marca ya que será mas factible que éstas sean percibidas. Por el contrario, si el personaje es un ser viviente, en éste caso un ser humano, puede ser mas complicado que los valores de la marca sean transmitidos eficien- 
temente a través de él, ya que por su condición humana, posee características intrínsecas que son inalienables. En este punto, es importante determinar que éstas características intrínsecas sean compatibles, no sólo con la marca, sino también con los esquemas estéticos de las audiencias objetivo con las cuales deberá conectarse. De lo contrario, pudieran causarse grandes distorsiones en la percepción de las audiencias, generando el rechazo y la pérdida del valor emocional que el consumidor le confiere a la marca.

En cuanto al diseño mensaje a enviar, los resultados indican una mayor identificación y recordación si el recurso utilizado es el humor, en situaciones y locaciones afines y cercanas con el entorno social de los segmentos. Contrariamente, la intriga y expectativa prolongada demostraron ser menos efectivas, ya que los consumidores tienden a completar el mensaje de acuerdo a sus mapas conceptuales, obteniendo de esta forma una mayor dispersión en la percepción esperada. Aquí es importante analizar el impacto de los medios a utilizar, ya que si bien la televisión pareciera ser el más adecuado para poder transmitir las características de un personaje de marca (imagen y audio), por ser un medio masivo, existe el riesgo de dispersión en un número mayor de segmentos alcanzados, que interpretaran el mensaje de una forma distinta a la esperada por la organización emisora.

Finalmente, el impacto de los personajes o iconos de marca a nivel de ventas no quedó claramente expuesto en los hallazgos de la investigación. Si bien cada grupo de consumidores se identificó claramente con alguno de los personajes e identificó la cerveza de su preferencia, estos dos aspectos del consumo rara vez coincidieron. Esta incongruencia, entre la preferencia del producto y la preferencia (y recordación) del personaje de marca demuestra que establecer la relación emocional no es garantía de que el comportamiento del consumidor se traducirá en una compra; validando los constructos de la Teoría del Capital de Marca (Saavedra, 2004) y la "Jerarquía de los Efectos Comunicacionales" de la Teoría del Comportamiento del Consumidor (Loudon y Della Bitta, 1995; Sheth, et al. 1999; Ratneshwar et al, 2000; Bagozzi et al, 2002; Sheth et al, 2003; Solomon, 2003).

\section{Referencias Bibliográficas}

Aaker, David A. (1992). "The value of brand equity". Journal of Business Strategy. Vol. 13, No. 4, USA. Pág. 27-32.

Bagozzi, Richard; Gurhan-Canli, Zynep y Priester, Joseph R. (2002). The Social Psychology of Consumer Behaviour (Applying Social Psychology). USA. Open University Press. Págs. 224.

Belch, George y Belch, Mlchael (1998). Advertising and Promotion. USA. Irwin/McGraw-Hill. 4ta. Edición. Págs. 762.

Benassini, Laura (2001). Introducción a la Investigación de Mercados. México. Prentice Hall-Pearson Educación México. Págs. 204.

Boone, Louise y Kurtz, David (2003). Contemporary Marketing. USA. SouthWestern College Pub. 11ma. Edición. Págs. 624.

Brady, Diane; Hof, Robert D.; Reinhardt, Andy; Ihlwan, Moon; Holmes, Stanley y Capell, Kerry (2004). Cult Brand, The 
Best Global Brand http://www.businessweek.com/magazine/content/ 04 31/b3894094.htm Revisado Febrero 2005.

Engel, James; Blackwell, Roger y Miniard, Paul (1990). Consumer Behavior USA. Dryden Press. 6ta Edición. Págs. 592.

Farquhar, Peter. (1989). Managing brand equity. Marketing Research. Vol. 1, No. 3. USA. American Marketing Association Publications. Pág. 24-33.

Fernández, Pablo (2002). "Valuation of Brands and Intellectual Capital". Research Paper No. 456. España. IESE Universidad de Navarra.

Gallo Carvajal, Gloria (2000). Posicionamiento: EL Caso Latinoamericano. Colombia. McGraw-Hill Interamericana. Págs. 196.

Grant, John (2000). The New Marketing Manifesto: The 12 Rules for Building Successful Brands in the 21st Century (Business Essentials). USA. Texere Publishing. 248 Págs.

Initiative Futures (2005). Spheres of Influence 2004. Global Advertising Expenditure Trends Report. Initiative Futures Worldwide http://64.233.161.104 /search?q=cache:RmF7XJauu10 J:www.interpublic.com/read_file. php\%3Fdid\%3D48+global+advertising+initiative+Futures+research \&hl=es Revisado, Febrero 2005.

Joachimsthaler, Erich y Aaker, David (2002). "Crear marcas sin utilizar medios de comunicación" en Varios Gestión de Marcas. España. Ediciones Deusto, S.A./Harvard Business Review. Págs. 232.

Keller, Kevin. (1993). "Conceptualizing, measuring, and managing customer-based brand equity". Journal of Marketing. Vol. 57, No. 1. USA. American Market- ing Association Publications Pág. 1-22.

Klein, David y Donaton Scott (2003). The Advertising Century: Top 10 advertising icons of the century. http://www.adage.com/century/ad_ icons.html (Revisado Diciembre 2004).

Krugman, H.E. (1965). "The Impact of Television Advertising: Learning Without Involvement". Public Opinion Quarterly. USA. Vol. 29. Págs. 349-56.

Krugman, H.E. (1966). "Answering Some Unanswered Questions in Measuring Advertising Effectiveness". Proceedings. USA. Advertising Research Foundation. Págs. 18-23.

Krugman, H.E. (1966-67). "The Measurement of Advertising Involvement”. Public Opinion Quarterly. USA. Vol. 30. Págs. 583-596.

Leigh, James y Gabel, Terrance (1992) "Symbolic Interactionism: Its Effects on Consumer Behavior and Implications for Marketing Strategy". The Journal of Consumer Marketing. Vol. 9, No. 1. USA. Pag. 27-39.

Loudon, David y Della Bitta, Albert (1995). Comportamiento del Consumidor. México. McGraw-Hill Interamericana de México. 4ta. Edición. 834 Págs.

Low, George S. y Lamb Jr., Charles W. (2000). "The measurement and dimensionality of brand associations" Journal of Product \& Brand Management. Vol. 9, No. 6. USA. Emerald Group Publishing Limited. Págs. 350-368.

Publicidad y Mercadeo (2004). "Anunciantes de tres soles". No. 575. Marzo.

Ratneshwar, S.; Glen Mick, David y Huffman, Cynthia. Why of Consumption: Contemporary Perspectives on Consumer Motives, Goals and Desires. USA. Routledge Interpretive Market Research Series. Págs. 330. 
Rodríguez, Maㅡ Carmen; Cervantes, Miguel y González, Ana M‥ (2002) "Análisis de la Implicación con la Denominación de Origen desde una Perspectiva Cognitiva. La Implicación como criterio de Segmentación del Mercado". Departamento de Dirección y Economía de la Empresa, Comercialización e Investigación de Mercados, España. Universidad de León.

Saavedra Torres, José Luis (2004). "Capital de Marca desde la Perspectiva del Consumidor". Revista Venezolana de Gerencia. Año 9. No. 27. Venezuela. FACES-Universidad del Zulia. Pág. 508-530.

Sabino, Carlos (2000). Metodología de la Investigación. Caracas. Epistemi.

Schmitt, Bernd H. (1999). Experiential Marketing: How to Get Customers to Sense, Feel, Think, Act, and Relate to Your Company and Brands. USA. The Free Press. 253 Págs.

Seetharaman, Ananth.; Mohd Nadzir, Zainal Azlan Bin y Gunalan Seethu. (2001). A conceptual study on brand valuation. Journal of Product \& Brand Management. Vol. 10, No. 4. USA.
Emerald Group Publishing Limited. Pág. 243 - 256.

Sheth, Jagdish; Mittal, Banwari y Newman, Bruce (1999) Customer Behavior: Consumer Behavior and Beyond. USA. Harcourt Brace College Publishers. Págs. 799.

Sheth, Jagdish; Mittal, Banwari y Newman, Bruce (2003) Customer Behavior: A Managerial Perspective. USA. South-Western College Pub. 2da. Edición. Págs. 550.

Solomon, Michael R. (2003). Consumer Behavior. USA.Prentice Hall. 6ta. Edición. Págs. 592.

Stanton, William; Etzel, Michael y Walker, Bruce (2000) Fundamentos de Marketing. México. McGraw-Hill Interamericana 11ra Edición. Págs. 707.

Tybout, Alice y Carpenter, Gregory (2002). "Crear y Administrar Marcas" en lacobucci, Dawn (Coordinador) Marketing según Kellogg. España. Vergara Editores/Business. Págs. 504.

\section{ENTREVISTAS}

Melillo, Víctor. Vicepresidente Creativo de Concept-Lowe Publicidad (05-2004). 